\title{
Some Comments on Molecular Partition Functions
}

\author{
Christopher M. Sharp*
}

\section{DISCLAIMER}

\begin{abstract}
This report was prepared as an account of work sponsored by an agency of the United States Government. Neither the United States Government nor any agency thereof, nor any of their employees, makes any warranty, express or implied, or assumes any legal liability or responsibility for the accuracy, completeness, or usefulness of any information, apparatus, product, or process disclosed, or represents that its use would not infringe privately owned rights. Reference herein to any specific commercial product, process, or service by trade name, trademark, manufacturer, or otherwise does not necessarily constitute or imply its endorsement, recommendation, or favoring by the United States Government or any agency thereof. The views and opinions of authors expressed herein do not necessarily state or reflect those of the United States Government or any agency thereof.
\end{abstract}


by

Christopher M. Sharp

ABSTRACT

In models of cool stellar atmospheres where molecules are important, molecular spectroscopic data can be used to calculate partition functions, from which equilibrium constants hence abundances can be obtained. In this report, it is shown that simple analytic approximations can be used to calculate very easily the partition functions of diatomic molecules, and comparisons are made for the two particularly important astrophysical molecules, $\mathrm{H}_{2}$ and $\mathrm{CO}$, with other work where the partition functions are calculated by explicitly summing over a very large number of energy levels. It is found that these analytic approximations give excellent agreement with more detailed calculations and are certainly adequate for many purposes. This method is very convenient, as only a few spectroscopic constants are needed, and the analytic formulae are very easily evaluated.

In a recent paper by Kurucz (1985), molecular partition functions and equilibrium constants of $\mathrm{H}_{2}$ and $\mathrm{CO}$ were given for temperatures from $1000 \mathrm{~K}$ to $9000 \mathrm{~K}$, over which molecule formation has to be considered in stellar atmospheres, and comparisons were made with results from other references.

The partition functions given by Kurucz were obtained by explicitly summing over large numbers of rotational and vibrational levels in the lowest three electronic states of $\mathrm{H}_{2}$ and $\mathrm{CO}$, as given by Dabrowsky (1984) for $\mathrm{H}_{2}$ and by Field et al. (1972) and Mantz et al. (1975) for CO. Although the partition functions so obtained would be expected to be very accurate, we question here whether it is necessary to go to such lengths and present an alternative rapid analytic method based on the work of Kassel (1933a) and (1933b). Applying this method to the data given by Huber and Herzberg (1979) for $\mathrm{H}_{2}$ and $\mathrm{CO}$, we obtain results that compare favorably with the results given by polynomial fits from various references given for comparison by Kurucz (1985), although our results are not as accurate as those calculated by Kurucz directly.

The total internal partition function of a diatomic molecule is given to a very good approximation by 
$\mathrm{Q}=\frac{i}{\sigma} \sum_{i} \mathrm{Q}_{\mathrm{E}_{i}} \mathrm{Q}_{\mathrm{V}_{\mathrm{i}}} \mathrm{Q}_{\mathrm{R}_{i}} \mathrm{e}^{-\mathrm{T}_{\mathrm{o}} \mathrm{hc} / \mathrm{kT}}$

where $\sigma=1$ of 2, respectively, for heteronuclear and homonuclear molecules and is the symmetry number,

$\mathrm{Q}_{\mathrm{E}_{i}}=\left(2-\delta_{\Lambda_{i}, 0}\right)(2 \mathrm{~S}+1)$, the electronic partition function of the $i^{\text {th }}$ electronic state,

$\mathrm{Q}_{\mathrm{V}_{i}}=$ vibrational partition function of the $i^{\text {th }}$ electronic state,

$\mathrm{Q}_{\mathrm{R}_{i}}=$ rotational partition function of the $i^{\text {th }}$ electronic state,

$\mathrm{T}_{\mathrm{o}_{i}}=$ energy in $\mathrm{cm}^{-1}$ of the $i^{\text {th }}$ electronic state, after correcting for the zero-point energies.

Electronic energies are usually given as $\mathrm{T}_{e}$, the energy at the bottom of the potential well of the excited electronic state measured from the bottom of the potential well of the ground electronic state. However, because the required energy in Eq. (1) is $T_{0}$, the energy of the lowest vibrational level in the excited electronic state measured from the lowest vibrational level in the ground electronic state, the conversion to $\mathrm{T}_{\mathrm{o}}$ by correcting for the zero-point vibrational energies is given by

$\mathrm{T}_{0}^{\prime}=\mathrm{T}_{\mathrm{e}}^{\prime}+\frac{1}{2}\left(\omega_{\mathrm{e}}^{\prime}-\omega_{\mathrm{e}}^{\prime \prime}\right)-\frac{1}{4}\left(\omega_{\mathrm{e}}^{\prime} \mathrm{x}_{\mathrm{e}}^{\prime}-\omega_{\mathrm{e}}^{\prime \prime} \mathrm{x}_{\mathrm{e}}^{\prime \prime}\right)+\frac{1}{8}\left(\omega_{\mathrm{e}}^{\prime} \mathrm{y}_{\mathrm{e}}^{\prime}-\omega_{\mathrm{e}}^{\prime \prime} \mathrm{y}_{\mathrm{e}}^{\prime \prime}\right)+\cdots$

where the single and double primes denote the excited and ground electronic states, respectively. By definition, $\mathrm{T}_{\mathrm{e}}=0$ when energies are measured from the bottom of the potential wells, and $\mathrm{T}_{0}^{\prime \prime}=0$ when energies are measured from the lowest vibrational levei. For most cases $\mathrm{T}_{0}^{\prime}-\mathrm{T}_{\mathrm{e}}^{\prime} \ll \mathrm{T}_{\mathrm{e}}^{\prime}$, as is the case here with $\mathrm{H}_{2}$ and $\mathrm{CO}$.

By Kassel (1933a), the rotational partition function for states of odd multiplicity is given by

$$
Q_{R}=\frac{1}{b}+\frac{1}{3}+\frac{b}{15}+\frac{2 d}{b^{3}}\left(1+\frac{6 d}{b^{2}}\right)+\cdots,
$$

where $\mathrm{b}=\mathrm{B}_{\mathrm{e}} \mathrm{hc} / \mathrm{kT}, \mathrm{d}=\mathrm{D}_{\mathrm{e}} \mathrm{hc} / \mathrm{kT}$, and $\mathrm{B}_{\mathrm{e}}$ and $\mathrm{D}_{\mathrm{e}}$ are the rotational rigid and nonrigidity constants respectively. Equation (3) gives more accurate values 
of $\mathrm{Q}_{\mathrm{R}}$ over a larger temperature range than the usually given $\mathrm{kT} / \mathrm{B}_{\mathrm{e}}$ he, which is the first term.

By Kasse1 (1933b), the vibrational partition function is given by

$$
\begin{aligned}
Q_{V} & =\frac{1}{(1-Z)}+W_{0} X_{0} \frac{Z(1+Z)}{(1-Z)^{3}}+\left(W_{0} X_{0}\right)^{2} \frac{Z\left(1+11 Z+11 Z^{2}+Z^{3}\right)}{2(1-Z)^{5}} \\
& +\left(W_{0} X_{0}\right)^{3} \frac{Z\left(1+57 Z+302 Z^{2}+302 Z^{3}+57 Z^{4}+Z^{5}\right)}{6(1-Z)^{7}} \\
& -W_{O} Y_{0} \frac{Z\left(1+4 Z+Z^{2}\right)}{(1-Z)^{4}}-\left(W_{0} X_{0}\right)\left(W_{0} Y_{0}\right) \frac{Z\left(1+26 Z+66 Z^{2}+26 Z^{3}+Z^{4}\right)}{(1-Z)^{6}}+\cdots,
\end{aligned}
$$

where

$$
\begin{aligned}
\mathrm{Z} & =\mathrm{e}^{-\mathrm{W}_{\mathrm{o}}}, \\
\mathrm{W}_{\mathrm{O}} & =\left(\omega_{\mathrm{e}}-\omega_{\mathrm{e}} \mathrm{x}_{\mathrm{e}}+\frac{3}{4} \omega_{\mathrm{e}} \mathrm{y}_{\mathrm{e}}\right) \mathrm{hc} / \mathrm{kT}, \\
\mathrm{W}_{\mathrm{o}} \mathrm{X}_{\mathrm{O}} & =\left(\omega_{\mathrm{e}} \mathrm{x}_{\mathrm{e}}-\frac{3}{2} \omega_{\mathrm{e}} \mathrm{y}_{\mathrm{e}}\right) \mathrm{hc} / \mathrm{kT}, \\
\mathrm{W}_{\mathrm{O}} \mathrm{Y}_{\mathrm{o}} & =\omega_{\mathrm{e}} \mathrm{y}_{\mathrm{e}} \mathrm{hc} / \mathrm{kT},
\end{aligned}
$$

and higher order anharmonic constants are neglected. Over the temperatures relevant for stellar atmospheres, higher order terms and cross terms in $\mathrm{Eq}$. (3) and Eq. (4) are negligibie.

If we calculate the partition functions of $\mathrm{H}_{2}$ and $\mathrm{CO}$ for only the ground electronic states, where $Q_{E}=1$ for both molecules and $\sigma=2$ and 1 for $\mathrm{H}_{2}$ and $\mathrm{CO}$, respectively, the error for $\mathrm{H}_{2}$ compared to Kurucz's values varies from -2.48 at $1000 \mathrm{~K}$ to -6.48 at $9000 \mathrm{~K}$, which is considerably better than most of the values given by Bohn and Wolf (1984) and Sauval and Tatum (1984). At about the solar photospheric temperature of $6000 \mathrm{~K}$, our error of -5.28 is half those of the above references. Our partition functions for co deviate from those of Kurucz by $-0.47 \%$ at $1000 \mathrm{~K}$ and increase in magnitude to -1.978 at $6000 \mathrm{~K}$ and $-3.55 \%$ at $9000 \mathrm{~K}$, and are comparable to the errors given by Kurucz for the two references, except at high temperatures where the values of Bohn and Wolf are rather better. 
These calculations were then repeated with the inclusion of up to two excited electronic states of $\mathrm{H}_{2}$ and three of $\mathrm{CO}$. As the first excited state of $\mathrm{H}_{2}$ is very high in energy, the contribution il and higher states make to the total internal partition function is completely negligible over all temperatures considerer, so the inclusion of higher states of $\mathrm{H}_{2}$ in the work of Kurucz is redundant. The lower excited states of $\mathrm{CO}$ are lower in energy than $\mathrm{H}_{2}$ but are still at high enough energy to have a small effect on the total partition function. As successively higher excited states are taken into account, the partition function of $\mathrm{CO}$ at $9000 \mathrm{~K}$ increases, and with three excited states included, the magnitude of our deviation from Kurucz decreases to $-2.99 \%$. However, below about $6000 \mathrm{~K}$ the excited states have a negligible effect on the partition function.

Although any method for calculating partitions functions that relies on asymptotic formulae or polynomial fits can obviously never be as accurate as directly summing over the energy levels, the method presented here is quick and easy to use and gives results that are certainly superior for $\mathrm{H}_{2}$ compared to the results of Bohn and Wolf and those of Sauval and Tatum and are at least comparable for co except at high temperatures where our results are not as good. However, near the upper temperature range of the table, the abundances of $\mathrm{H}_{2}$ and $\mathrm{CO}$ are very small compared to the free atoms, so in many applications the errors in the partition functions are not very important.

As our partition functions are calculated directly from the spectroscopic constants, our method is far more convenient than calculating partition functions by some other method over a temperature range, then fitting a polynomial, particularly if a long list of molecular data is considered. Also excited electronic states need only be considered when they would contribute significantly to the total internal partition function over the temperature range of interest, which is not the case for $\mathrm{H}_{2}$.

\section{ACKNOWLEDGEMENT}

I wish to thank Dr. W. F. Huebner for his comments on this manuscript. 


\section{REFERENCES}

Bohn, H. U., and Wolf, B. E. 1984, Astr. Ap., 130, 202.

Dabrowsky, I. 1984, Can. J. Phys, 62, 1639.

Field, R. W., Wicke, B. G., Simmons, J. D., and Tilford, S. G. 1972, J. Mol. Spect., 44, 383 .

Huber, K. P., and Herzberg, G. 1979, Molecular Spectra and :Holecular Structure, IV. Constants of Diatomic Molecules, Van Nostrand Reinhold Co.

Kassel, L. S. 1933, J. Chem. Phys., 1, 576.

Kasse1, L. S. 1933, Phys. Rev., 43, 364.

Kurucz, R. E. 1985. Harvard-Smithsonian Observatory, Center for Astrophysics, Preprint Series No. 216?.

Mantz, A. W., Maillard, J.-P., Roh, W. B., and Rao, K. N. 1975, J. Mol. Spect., 57, 155 .

Sauval, A. J., and Tatum, J. B. 1984, Ap. J. Suppl., 56, 193. 